\title{
Genomic Equivalents
}

National Cancer Institute

\section{Source}

National Cancer Institute. Genomic Equivalents. NCI Thesaurus. Code C161493.

A unit defined as the number of whole organism genomes in a sample. 